Int. J. Electrochem. Sci., 13 (2018) 4027 - 4045

International Journal of

ELECTROCHEMICAL

SCIENCE

www.electrochemsci.org

\title{
Mesoporous Hydroxylated Carbon Nanofibers as an Effective Cathode Scaffold to Enhance the Lithiation-Delithiation Reversibility of Lithium-Sulfur Batteries
}

\author{
Faqi Yu, He Zhou, Yilin Li, Qiang Shen* \\ Key Laboratory for Colloid and Interface Chemistry of Education Ministry, School of Chemistry and \\ Chemical Engineering, Shandong University, Jinan 250100, China. \\ *E-mail: qshen@sdu.edu.cn.
}

doi: $10.20964 / 2018.05 .47$

Received: 2 January 2018 / Accepted: 28 February 2018 / Published: 10 April 2018

Taking a reversible electrochemical reaction of elemental sulfur towards metallic lithium into consideration, it seems to be inappropriate to calculate $\mathrm{Li}^{+}$-ion diffusion coefficient $\left(\mathrm{D}_{\mathrm{Li}}\right)$ within a solid-state cathode of carbon-sulfur composites using the concentration of lithium ions in electrolyte solution. In this paper, cross-linked non-porous carbon nanofibers (CNF) and mesoporous hydroxylated carbon nanofibers (m-HCNF) are prepared and comparatively utilized as sulfur-loading matrices to improve the lithiation-delithiation reversibility between molecular $\mathrm{S}_{8}$ and metallic lithium. When model cells are assembled at a constant dosage of electrolyte $(30 \mathrm{~mL})$ per gram of sulfur, at open-circuit voltage the $\mathrm{D}_{\mathrm{Li}}$ value of a lithium-sulfur $(\mathrm{Li}-\mathrm{S})$ battery cathode can be estimated according to the $\mathrm{S}_{8}$ concentration therein: $3.51 \times 10^{-15} \mathrm{~cm}^{2} \mathrm{~s}^{-1}$ for the low sulfur-loading cathode S/CNF (47.0 $\mathrm{wt} \%) ; 4.21 \times 10^{-15} \mathrm{~cm}^{2} \mathrm{~s}^{-1}$ for the high sulfur-loading electrode S/m-HCNF $(\sim 62.0 \mathrm{wt} \%)$. At $0.5 \mathrm{C}$ the initial Coulombic efficiency of S/m-HCNF (96.9\%) is higher than that of S/CNF (88.8\%), and thereafter the better cycling stability and rate performance of the former coincide well with the varying $\mathrm{D}_{\mathrm{Li}}$ values. In a word, these indicate an enhanced lithiation-delithiation reversibility of composite S/mHCNF for high-performance Li-S batteries.

Keywords: Lithium-ion diffusion coefficient; Lithiation-delithiation reversibility; Mesoporous carbon nanofiber; Lithium-sulfur batteries.

\section{FULL TEXT}

(C) 2018 The Authors. Published by ESG (www.electrochemsci.org). This article is an open access article distributed under the terms and conditions of the Creative Commons Attribution license (http://creativecommons.org/licenses/by/4.0/). 